\title{
O território, visto por outros olhos
}

\author{
Oscar Calavia Sáez \\ Universidade Federal de Santa Catarina
}

\begin{abstract}
RESUMO: Em relatos míticos e na praxe dos Yaminawa do Acre - desde há muito tempo caraterizados como "problema" pela sua difícil inserção no sistema territorial indígena que os converte em indesejados moradores da cidade -, procuram-se os traços de uma noção de "território" diferente daquela que aparece no discurso do movimento indígena, e a rigor incompatível com a norma de delimitação e apropriação da terra presente na nossa ordem jurídica. Essa noção é definida como perspectiva e fractal, topológica mais que espacial ou ecológica; nela, são as relaçóes as que criam um "território" em lugar de desenvolver-se nele, e os constantes deslocamentos assinalam não um "nomadismo" - com a prevalência de limites sociais atravessando limites espaciais -, mas o uso das distâncias para a rápida recombinação dos arranjos sociais.
\end{abstract}

PALAVRAS-CHAVE: Yaminawa, território, fractalidade, perspectivismo, topologia, Amazônia.

Neste artigo, os Yaminawa fornecem um caso crítico para pensar sobre os territórios indígenas no Brasil, sobre os processos de territorialização e definiçáo de territorialidade e sobre o que, no meio desses processos pautados por um regime jurídico de tradição europeia, poderia ser uma percepção diferente da relação com o solo (uma outra territorialidade). Para mim, são o melhor exemplo desses processos, porque é através dessa experiência contraditória que, desde uma pesquisa de campo realizada em inícios dos anos noventa, tem se formado a minha percepção dessas questóes ${ }^{1}$. Experiências posteriores como orientador de pesquisas 
OSCAR CALAVIA SAEZ. O TERRITÓRIO, VISTO POR OUTROS OLHOS

etnográficas - muito especialmente entre os Guarani do sul do Brasil - me sugerem que o exemplo Yaminawa é fértil para abordar outras situaçóes demográfica, geográfica e historicamente muito diferentes.

\section{Os nomes, as aldeias, a cidade}

Deixarei aos próprios Yaminawa a tarefa de se apresentar. $\mathrm{O}$ texto a seguir, uma citação muito extensa, provém do primeiro trabalho acadêmico de autoria de um Yaminawa, a saber Julio Raimundo Isudawa, que à época da minha pesquisa era um dos professores da escola indígena na Aldeia Cabeceiras do rio Acre, e que no final desse período tornou-se o seu chefe:

O nome Jaminawa foi dado pelo povo não-índio. Na verdade, essa é a origem do nome. O nome Jaminawa vem de Yaminawa, que significa "povo do machado". Deram esse nome para nosso grupo porque os Jaminawa traziam muitos machados de pedra para a floresta. Tsapadawa, Xixidawa, Deadawa são os três povos indígenas que antigamente formaram os Jaminawa. Esse povo conhecido como Jaminawa do lado do Brasil é conhecido no Peru e na Bolívia pelo nome Yaminawa ou Marinawa. Também outros povos pano conheciam os Tsapadawa como Kutadawa. Mas é um povo que vem deixando trilhas por boa parte das cabeceiras dos rios que banham a Amazônia Ocidental. Ainda hoje, os Jaminawa habitam as cabeceiras dos rios, principalmente nas fronteiras com o Peru, com a Bolívia e no próprio Brasil. Assim, o atual povo jaminawa vive ainda na fronteira com os dois países vizinhos.

Para o povo jaminawa não existiam limites da terra. Todas as florestas verdes eram de todos, não existia dono, eram de quem vivia dentro dela. Todos eram subordinados a ela. Era tudo saudável, não existia poluição. Sim, 
REVISTA DE ANTROPOLOGIA, SÃO PAULO, USP, $20 \mathrm{I}$, V. 58 N $\mathrm{N}^{\mathrm{O}} \mathrm{I}$.

existia desenvolvimento do povo. Sem ganância com dinheiro, não existia egoísmo, nem escravidão com ninguém. Todos tinham direitos iguais, e a educação era na oralidade. O povo tinha uma vida saudável, não tinha ninguém superior e nem inferior a outros. Atualmente o povo jaminawa guarda os seus valores tradicionais, e permanece resistindo, sobrevivendo. Os atuais Jaminawa vivem em seis terras indígenas, espalhados pelo estado do Acre e sudoeste do Amazonas. São elas: Terra Indígena Cabeceira do Rio Acre, Terra Indígena Mamoadate, Terra Indígena Guajara, Terra Indígena Kayapuka, Terra Indígena Caeté e Terra Indígena São Paulino.

Uns cento e cinquenta anos atrás as famílias jaminawa viviam nas terras que conquistaram, e viviam os seus costumes tradicionais. Sem se preocupar com as coisas industrializadas, só praticavam os seus costumes. Mas o desenvolvimento ocidental foi multiplicando e as coisas industrializadas foram sendo oferecidas, e os indígenas jaminawa foram consumindo e as coisas foram aumentando. Até na política, os Jaminawa começaram a se envolver. Atualmente, de 100\% dos Jaminawa que viviam nas terras indígenas, cerca de $20 \%$ estão nos municípios acreanos. Uma boa parte desses Jaminawa foram morar na cidade por causa das promessas dos políticos dos partidos. Algumas famílias saíram da terra indígena por achar que poderiam viver melhor na cidade. Muitos dos Jaminawa se atrapalharam, porque a vida na cidade náo combinou com a sua cultura e os seus costumes. Em primeiro lugar, as pessoas que migraram geralmente não conseguiram emprego, as moradias não foram suficiente para eles morarem, muitas crianças tornaram-se mendigos. Tudo isso o povo jaminawa vem enfrentado dentro da sociedade. Com esse tipo de migração nós estamos enfraquecendo a identidade do nosso povo. É isso que a sociedade acha, que os indígenas têm que desenvolver junto com a sociedade para o melhor do país. Não nos reconhecem como povos diferentes, oferecem tantas coisas boas, deixando também muitas coisas ruins dentro da terra indígena. O povo jaminawa ainda tem muitas coisas dos conhecimentos tradicionais. 
OSCAR CALAVIA SAEZ. O TERRITÓRIO, VISTO POR OUTROS OLHOS

O povo jaminawa não vai se acabar tão fácil na mão do homem branco. Podemos até sofrer, mas nunca deixar de ser Jaminawa! Sabemos que as tecnologias são para acabar com certas culturas do povo nativo. Os massacres continuam, mas não são mais como antigamente.

O povo jaminawa antes do seu contato vivia e habitava o território peruano, na floresta amazônica. Os mesmos eram nômades, mas hoje, com a criação de uma terra demarcada, os Jaminawa lutam por uma vida melhor no Acre. Sem contar com ao lado do país vizinho, seja o Peru, seja a Bolívia. (Jaminawa, 2013: 12-13)

Acrescento a essa descrição alguns comentários. À época da minha pesquisa, entre 1992 e 1993, os Yaminawa acabavam de obter um considerável sucesso na reivindicação de suas terras. Eram essas duas, a T.I. Mamoadate, no rio Iaco, e a T.I. Cabeceiras do Rio Acre.

A Terra Indígena Mamoadate, onde os Yaminawa conviviam com um grupo Manchineri - de língua Arawak e com um histórico de cooperação com os patrôes do seringal e com a Missão Novas Tribos -, foi a primeira a ser identificada (1977) e demarcada (1986), por uma Funai que acabava de ser implantada no Acre pouco mais de um ano antes. Para a nossa melhor percepção das emergências étnicas, é bom lembrar que o Acre - que muitos podem ver agora como uma espécie de "estado indígena” pelo número e a visibilidade de suas etnias - era ainda nos anos setenta considerado um território "sem índios", porque o grande relato do boom da borracha fazia supor que eles teriam sido varridos já em início do século xx pela onda da migração nordestina.

A Terra Indígena Cabeceiras do Rio Acre foi, à diferença de Mamoadate, o primeiro fruto de um ativismo indígena já em cooperação com o indigenismo não oficial. Os Yaminawa - cujo principal porta-voz na época era José Correia Tunumã - reclamavam de se ver incluídos num mesmo território com os Manchineri, inimigos que outrora os 
REVISTA DE ANTROPOLOGIA, SÃO PAULO, USP, $20 \mathrm{I} 5$, V. $58 \mathrm{~N}^{\circ} \mathrm{I}$.

perseguiram a mando dos patrôes brancos, e que obtinham dos seus aliados (tanto a Funai quanto a Missão) um trato mais vantajoso. Foi esse o moto principal da mudança para a aldeia do rio Acre, onde já residiam à época algumas famílias yaminawa. Um nutrido grupo de Yaminawa migrou para esse rio, e obteve o reconhecimento da terra e a instalaçáo (precária, é verdade, como pude comprovar) de serviços tais como escola e posto de saúde. A nova T.I. foi identificada em 1987 e definitivamente regularizada em 1998, depois de ter sido consideravelmente ampliada (de fato, quase quadruplicada) em 1992, incorporando áreas intersticiais entre ela e as unidades de conservação próximas ${ }^{2}$. O argumento dos "Manchineri inimigos" precisa ser matizado à luz da experiência: junto com os Yaminawa, um grupo considerável de Manchineri se deslocou também para o eio Acre e compartilhou durante anos a terra nominalmente atribuída àqueles, enquanto aproximadamente a metade dos Yaminawa continuou morando em Mamoadate na vizinhança dos Manchineri restantes. Anos depois, os Yaminawa nunca incluíam entre os motivos alegados para o deslocamento esse desprazer pela vizinhança do outro grupo, que no seu momento foi importante na reivindicação: aludiam, antes, a desavenças com o cacique e, também, note-se, à maior proximidade da nova aldeia da cidade dos brancos, uma circunstância desejável. De fato, esse início bem-sucedido do movimento indígena entre os Yaminawa foi também o início desse "problema yaminawa" que é realçado no relato de Júlio Isudawa. Seguindo a trilha dos seus representantes que permaneciam na capital, Rio Branco, os Yaminawa começaram a se deslocar até à cidade e a se instalar nela durante longos períodos na incômoda posição de "mendigos". Desde entáo, a história yaminawa vem sendo pontuada por essa periódica migraçáo à cidade que convive, já há muito, com uma população yaminawa regularmente urbana. A reivindicação, árdua porém várias vezes bem sucedida, de novos territórios, aconteceu uma e outra vez por meio dessa passagem 
OSCAR CALAVIA SAEZ. O TERRITÓRIO, VISTO POR OUTROS OLHOS

pelas ruas: novas aldeias foram formadas, às vezes longe dos dois núcleos originais, com os contingentes que se exilavam na cidade, de praxe após conflitos violentos entre "facçóes" que eventualmente se identificavam com esses subgrupos nomeados no texto. Um relatório de Walter Coutinho (2001; resumos e excertos dele em Calavia Sáez, 2004) descreve em detalhe esses processos ${ }^{3}$. Um TCC de autoria de Fátima Ferreira (2014), que na época desempenhou diversos trabalhos entre os Yaminawa para o governo do Acre, acrescenta a essa documentação uma visão desde a cidade e desde o ponto de vista de uma agente da administração.

No texto de Isudawa pode se reconhecer, é claro, a noção de autoctonia: a autoctonia é uma das principais exceçôes que se reconhecem à norma da terra como bem passível de apropriação. Essa afirmação da autoctonia é, no entanto, fraca: os Yaminawa não fazem questão de situar seu vínculo com a terra num evento no início dos tempos, nem sequer a rotulam de centenária ou milenar. Júlio Isodawa chega a falar em "terras que conquistamos" e usa um termo perigoso como "nomadismo", que faz parte muitas vezes do vocabulário usado para negar os direitos dos povos originários. A autoctonia, mais do que afirmada em si mesma, é representada por um dos seus principais atributos: o da conexão imediata com a natureza, essa virtude nativa dos povos autóctones.

O texto de Júlio Isudawa é, no entanto, contundente na sua afirmação de uma pluralidade de identidades mais ou menos ocultas por esse termo genérico, Jaminaua ou Yaminawa. Nisso, é fiel ao padrão da narrativa yaminawa, que raramente deixa de acompanhar qualquer relato com a enumeraçáo de uma longa lista de nomes étnicos, de praxe caracterizados como "subgrupos". Esses nomes são importantes nos processos de reivindicação de território, quando se alega que a demarcação foi feita e os territórios garantidos, mas tudo aconteceu segundo uma falsa percepção da identidade indígena: o processo reuniu povos muito diferentes, ou as facçóes em conflito de um mesmo povo. 
REVISTA DE ANTROPOLOGIA, SÃO PAULO, USP, $20 \mathrm{I} 5$, V. $58 \mathrm{~N}^{\circ} \mathrm{I}$.

\section{Outra cosmografia}

Passemos, porém, a um outro relato. Nesse caso, trata-se de uma narração oferecida por um interlocutor monolíngue, ou, a rigor, por dois: Clementino Yaminawa e Juarez Yaminawa. Ambos foram os narradores que com mais assiduidade se dispuseram a me contar essa história yaminawa que era o objeto central da minha pesquisa e, de fato, depois de um pedido genérico inicial, tomaram para si a tarefa de narrá-la em sua integridade. Os relatos, gravados em fita, foram traduzidos entre 1993 e 1994 por vários Yaminawa bilíngues, e especialmente por Arialdo Correia Jaminaua, agora já falecido e então um jovem de quinze anos.

Nawawaka Misti

Um dia os índios foram atrás de matar os nawa, que eram todos baixinhos; mas no caminho encontraram Nawawaka Misti, que estava puxando palha para fazer casa. Aí ele começou a dar vozes chamando os outros. Os índios se assustaram, fugiram correndo, e o mais medroso errou e pegou outro caminho. E os outros, voltando em casa disseram que ele tinha morrido. Mas não tinha morrido: andando e andando pelo mato se encontrou com a onça. Ela perguntou:

- $\mathrm{O}$ quê que tu faz aqui?

- Nawawaka Misti nos espantou; estou perdido, procurando a família.

Encontrou depois com Taska, o inhambu preto, que estava fazendo rede.

- Onde é que tu conseguiste esse algodão?

- Tirei aí no roçado de tua mulher.

Encontrou depois com o pica-pau:

- Ô txai, me ajuda! Estou perdido, procurando a família.

Pica-pau respondeu: 
OSCAR CALAVIA SAEZ. O TERRITÓRIO, VISTO POR OUTROS OLHOS

- Olha, me deixa que estou muito ocupado picando aqui, mas aí do lado mesmo tem um roçado, vai lá ver.

O homem foi lá, mas o roçado já era de Yurapibe [comedor de gente], que tinha casado com a mulher dele, e tinha botado arapuca para paca, e na arapuca caiu o coitado; e Yurapibe foi tirar lenha para assar ele. Aí que a mulher o encontrou: - Ô marido! O que tu estás fazendo aí? - E ela o tirou da arapuca e fugiram os dois.

Yurapibe voltou e viu o que tinha acontecido, e soltou atrás deles suas formigas devoradoras, Babish, e I-Uapé, a tocandira. Correram, correram e encontraram com Tsina, a cotia, quem disse para eles que lá perto estava a casa de Marinawa, onde poderiam se esconder, mas que não deviam comer a macaxeira dele, porque se comessem morreriam.

Foram lá, Marinawa os recebeu e preparou macaxeira que ofereceu pra ele: ele comeu e morreu.

$\mathrm{Na}$ versão de Juarez, que como de praxe era mais prolixa que a de Clementino, alteram-se, e alongam-se, os episódios centrais da peregrinação do protagonista, que na sua fuga...

... foi andando e topou a veada que estava parindo; e o filhote nasceu e começou a chorar: "E, e, e".

A veada perguntou:

- É menino ou menina?

E o índio respondeu:

- É menina.

- Pode tirar pra mim?

E o índio ajudou a veada.

Aí, andando à noite, encontrou umas jarinas que falavam entre sim, mas ele não entendeu nada do que diziam. Depois chegou num lugar onde umas queixadas se aqueciam ao fogo. 
REVISTA DE ANTROPOLOGIA, SÃO PAULO, USP, $20 \mathrm{I}$, V. 58 N $\mathrm{N}^{\mathrm{O}} \mathrm{I}$.

- Quem você é? - perguntaram.

- Sou Nawawaksta, estou perdido no mato.

- Estás muito perto de teu roçado - responderam as queixadas. - Amanhã irás lá. Podes ficar aqui junto ao fogo; mas não mexas nele.

Ele ficou lá. No começo tudo bem, mas depois mexeu no fogo, e na hora todas as queixadas escaparam esbaforidas. Sozinho, Nawawaka Misti decidiu seguir andando e encontrou com outro bando de queixadas; e a mesma conversa e o mesmo convite; e como da outra vez, ele não soube ficar quieto e as queixadas fugiram de novo.

Um pouco depois encontrou Txëspó, [o bacurau] que fiava algodão. Txëspó o convidou a dormir junto e a foder com ela:

- Mas com a condição de não tirar pelos de minha boceta.

Assim foi: dormiram juntos e começaram a foder, mas no meio Nawawaka Misti arrancou um pelo. Txëspó fugiu e voltou daí a pouco muito brava; mas topou voltar a começar; e o homem voltou a fazer o mesmo.

- Olha aí: se tu fizeres de novo, vou ir embora e não volto mais.

Mas Nawawaka Misti arrancou mais um pelo; e Txëspó foi embora mesmo, e não voltou mais. Nawawaka Misti seguiu assim caminhando, e no caminho topou com Ronoá [sucuri], que estava dormindo com toda sua família. Ronoá acordou e perguntou:

- Minha filha, foi você que mexeu?

- Não fui não, mãe.

- Meu filho, foi você que mexeu?

- Não fui eu, mãe.

E assim foi perguntando. E Nawawaka Misti, morto de medo de que Ronoá o comesse, escapou na ponta dos pés.

Aí ele encontrou com o pica-pau, que perguntou:

- Da onde você vem?

- Sou Nawawaka Misti. Estou perdido no mato e ando procurando minha família. 
OSCAR CALAVIA SAEZ. O TERRITÓRIO, VISTO POR OUTROS OLHOS

- Ah, tu não estás perdido coisa nenhuma: escuta, vou bater no último pau que tu derrubaste no teu próprio roçado.

O pica-pau então saiu voando, e logo ouviu-se o ruído: “taró, taró, taró”... Aí, Nawawaka Misti encontrou a onça, de noite. A onça estava doente e se desculpou por não ter comida para ele, mas o tranquilizou dizendo que estava muito perto de sua casa. A onça tinha duas mulheres: Txëspó, o bacurau, e Ónto, o caramujo. Mandou que cozinhassem macaxeira para seu primo que estava de visita, mas não dava certo porque Ónto sempre apagava o fogo. A onça ficou brava e bateu nas duas. Foi então mostrar o caminho para Nawawaka Misti.

- Vem atrás de mim: onde eu esturrar, é o lugar em que tu caçaste inhambu. Aí foi e esturrou: "iiiihh, iiiih...

- Ouviu onde foi?

E a onça foi mostrando o caminho. Mas Nawawaka Misti torrou a paciência dela porque a cada instante perguntava: "Ô txai, já chegamos? Ô txai, já chegamos?", e a onça acabou deixando-o sozinho no mato.

(Continua com o episódio do ogre canibal, aqui chamado Tatashpai, o carrapicho. Fogem. Falta o episódio dos animais de ferrão. A mulher não quer ir com ele, porque vai morrer. Come a mandioca de Marinawa. Morre.)

Algumas anotaçóes são necessárias. Nawawaka Misti significa, de um modo bastante literal, "Anão filho do branco". O leitor terá percebido que, de uma versão para outra, esse personagem muda de função: na primeira, aparece apenas para dispersar o grupo de agressores, depois do que o relato foca um personagem errabundo que não tem nome. $\mathrm{Na}$ segunda, e de um modo mais condizente com o título do relato, Nawawaka Misti é quem fica perdido e não consegue, depois do sobressalto, encontrar o caminho de volta à sua aldeia. Esses "índios" que aparecem no texto vertem ao português uma expressáo de valor pronominal, 
REVISTA DE ANTROPOLOGIA, SÃO PAULO, USP, $20 \mathrm{I}$, V. 58 N $\mathrm{N}^{\mathrm{O}} \mathrm{I}$.

nokoyura, que poderia se traduzir como "nosso corpo", ou "nossa gente", ou simplesmente "nós". Em várias ocasiôes, "Yura" tem sido entendido como autodenominaçáo de alguns grupos de língua Pano - foi o caso dos isolados contatados nos anos oitenta no Parque Nacional do Manu, no Peru, que foram inicialmente conhecidos como "Parquenahua" -, mas, como de fato esse termo pode se estender indefinidamente a partir de um ego - aos seus parentes próximos, a todo um grupo, a grupos afins, chegando a representar, perante o interlocutor branco, a totalidade dos índios -, essa solução de traduzi-lo pelo genérico "índio" é cabível. Por sua vez, nawa é o contrário polar de nokoyura: é o outro, o inimigo, e quando vertem suas histórias para o português, os Yaminawa oscilam entre manter esse termo ou vertê-lo como "branco". Os nawa são, em resumo, os inimigos, dos quais o branco é a encarnação por excelência mas não exclusiva. $\mathrm{O}$ autor destas linhas, durante a sua pesquisa, era chamado de nawa, mas nas narraçóes yaminawa abundam os nawa que vão à guerra atirando flechas com o corpo pintado ${ }^{4}$. Como vemos pela instabilidade da identidade do protagonista, o valor da história náo parece mudar se ele é parte do Nós ou do Outro.

Nawawaka Misti fala, como o texto de Julio Isudawa, de território. Porém, isso pode não ser reconhecido à primeira vista. É um shedipawó, uma história dos antigos. Para os Yaminawa, que não são dados à exegese e em geral relutam dissertar sobre os temas habituais das pesquisas, os shedipawó acabam sendo a resposta a todas as perguntas que um antropólogo costuma formular. Parentesco, regras de casamento? Técnicas xamânicas? Estão nos shedipawó. Qual é a relação entre animais e humanos? Quais são as funçôes de um chefe? Os shedipawo tratam disso. Este autor, quiçá como teria acontecido com muitos outros, teve dificuldades em aceitar essa indicação: o mundo dos shedipawó parecia em excesso fabuloso como para iluminar aspectos mais terrenos ou mais atuais da vida. Já faz tempo que está, porém, mais disposto a encontrar 
OSCAR CALAVIA SAEZ. O TERRITÓRIO, VISTO POR OUTROS OLHOS

continuidades entre ambos domínios. Feérico que pareça, Nawawaka Misti póe em cena elementos muito semelhantes aos da narração de Júlio Isudawa. Temos o equivalente das conquistas e o discorrer nômade pela selva: uma expedição de guerra, inglória como são quase todas as expediçóes de guerra, que deixa um protagonista extraviado na mata; e temos também a enumeração de uma série de personagens coadjuvantes, animais que falam, equivalentes dessa proliferação de grupos descrita no texto acadêmico. Essa última equivalência exige alguma explanação. Os subgrupos enumerados por Júlio Isudawa sáo identificados por nomes de animais como é a norma em quase todo o sudoeste amazônico: Isudawa fala, sem dúvida, de coletivos humanos, enquanto no shedipawó trata-se de animais, embora entendidos como humanos pelo seu comportamento. Algum dos coletivos animais coincidem com os etnônimos habitualmente citados pelos Yaminawa: em particular, Yawanawa (as queixadas) e Marinawa (as cutias). A noção de um perspectivismo multinaturalista, lançada por Eduardo Viveiros de Castro (2009), permite entender descriçóes que, à primeira vista. resultariam insuportavelmente ambíguas, onde não se sabe se está-se a falar em personagens humanos com nomes animais ou em personagens animais com costumes e atributos humanos. A clave multinaturalista - na qual é o corpo, e não a cultura, que diferencia uma espécie de outras, incluindo aí os diversos humanos - esclarece que isso não é um problema no relato, ou melhor, isso não é a clave do relato. Os Yaminawa contam, é verdade, muitos outros relatos em que essa clave perspectivista é tematizada, e a transformaçáo de humanos em animais e de animais em humanos ocupa o centro da trama e da a razão do seu desenlace. Não é assim em Nawawaka Misti, onde quase toda a ação transcorre indiferente à distinção entre o humano e o animal. $\mathrm{O}$ espaço em que o protagonista se move é, sim, a selva, mas não é a selva como "natureza" ou como território oposto ao povoado, senão o campo em que agem sujeitos, particulares ou coletivos, com que o protagonista 
REVISTA DE ANTROPOLOGIA, SÃO PAULO, USP, $20 \mathrm{I} 5$, V. 58 No I.

mantém todas as relações possíveis: parteiro, hóspede, amante, presa virtual, parente próximo... Se pudermos usar aqui um termo de Latour, a selva de Nawawaka Misti não é um meio ambiente, senão um conjunto de mediadores, cujo valor não depende criticamente de sua condição humana ou animal.

E os brancos? Se eles são uma condição de primeira ordem no relato de Isudawa, no shedipawó - neste shedipawó como em quase todos os outros - eles estáo absolutamente ausentes ou absolutamente presentes, a presença e a ausência manifestando-se como uma relaçáo de fundo e forma. A depender de que atualizemos ou não a tradução de nawa como "branco", Nawawaka Misti é uma história dos tempos pré-contato ou é uma narração dos tempos em que os Yaminawa erravam na floresta fugindo desse contato. Uma diferença essencial para nós, mas obviamente não para os Yaminawa, que subsumindo os "brancos" dentro de uma categoria de alteridade mais geral mostram que o mundo dos brancos, malgrado a forte atraçáo que exerce sobre eles, não é nada tấo novo assim sob o sol. Creio que a perícia do tradutor deve ser considerada, dando como boa essa equivalência entre os nawa e os brancos. Sua presença no relato é fugaz, porém fundamental: tudo começa com um frustrado ataque a esse nawa, que não voltam a aparecer. Que esses nawa sejam brancos ou não tem a mesma ordem de importância que a questão anterior, a de se essas queixadas, sucuris ou bacuraus são humanos ou não; de fato, eles, os nawa, são marcados por uma caraterística corporal, são anôes. Há, como é muito frequente nos relatos yaminawa, um aspecto humorístico nessa caraterização: segundo algum comentário que me foi feito ao relato, se "os índios" fogem de Nawawaka Misti, o anão, é porque ele, recolhendo jarina (palha para telhado), estava em pé sobre o tronco da jarina no momento em que deu as vozes de alarme aos seus parentes. Os índios correram espavoridos porque pensaram, então, que esse povo de anóes era, na verdade, um povo de gigantes. 
OSCAR CALAVIA SAEZ. O TERRITÓRIO, VISTO POR OUTROS OLHOS

Já em duas ocasiôes anteriores (Calavia Sáez, 2006, 2007) comentei o relato de Nawawaka Misti comparando-o com a Odisseia homérica. A comparação é menos arriscada e sobretudo menos frívola do que poderia parecer à primeira vista. Apesar de seu prestígio muito desigual, ambos são relatos míticos que consagram um modelo do espaço, uma cosmografia cognitiva e afetiva. No caso da epopeia grega, que deixou uma marca indelével na concepção europeia do mundo, conta-se também a difícil viagem de volta de uma guerra. O herói demora dez anos, perdido nos mares, atravessando terras desconhecidas, povoadas por monstros antropomorfos mas de costumes bestiais - ciclopes, lotófagos, sereias, a feiticeira Circe, que transforma em porcos os companheiros de Odisseu, etc. -, dos quais consegue escapar a muito custo graças à sua astúcia. O motor desse retorno é a fidelidade mútua entre o protagonista, que pese a tudo volta, e a sua terra original, Ítaca, onde sua esposa, pese a tudo, o espera. A apoteose do herói acontece com o extermínio dos pretendentes de sua esposa, que se instalaram ilegitimamente em sua casa.

O relato yaminawa distribui seu pessimismo de um modo muito diferente: o ponto de partida é também uma guerra, mas uma guerra fracassada, na verdade abortada antes de se iniciar, e a volta, também longa, percorre um mundo habitado por animais que se mostram quase que invariavelmente gentis e generosos; é a indiscrição incorrigível do protagonista o que o mantém em estéril peregrinação, em busca de um lar perdido que, na verdade, está sempre logo ali. A viagem de Nawawaka Misti é uma espécie de voyage autour de sa chambre pelo lado de fora, porque o herói nunca consegue identificar sua casa e seu roçado, que todos os outros veem claramente. Enfim, a chegada ao lar é decepcionante: ele o encontra ocupado por um monstro canibal e por uma esposa relativamente infiel, que no intervalo casou com o monstro, mas que apesar de tudo o livra da morte e, em uma das versóes, o acompanha na sua fuga. Tudo para nada, porque o protagonista acaba morrendo 
REVISTA DE ANTROPOLOGIA, SÃO PAULO, USP, $20 \mathrm{I} 5$, V. 58 No I.

envenenado na casa de mais um anfitriāo acolhedor, Marinawa, a cotia. Só aqui, aliás, a diferença entre animais e humanos se faz eficiente: o envenenamento se dá pela ingestão dessa "macaxera", que é na verdade mandioca brava, mortal para os humanos, mas que as cotias ingerem sem problemas: a comunidade de espírito fez o protagonista esquecer da diferença dos corpos...

Há um outro sentido em que a noção de perspectivismo ajuda a entender o relato. Refiro-me ao que também poderíamos chamar de fractalidade do espaço (Carneiro da Cunha, 1998). O mundo em que se move o protagonista de Nawawaka Misti é um mundo essencialmente desorientado. Não é um âmbito totalizado em que caiba assinalar pontos cardinais, regióes de uma totalidade orgânica: ao longo do seu pesadelo migratório, o protagonista náo está percorrendo nada parecido com o cosmos da Odisseia, e também nada parecido com os diferentes estágios de uma viagem iniciática ou xamânica. Nada indica tampouco uma progressão em direção ao desconhecido, ou um continuum de retorno ao espaço familiar. Muito pelo contrário, a sensaçáo de pesadelo que o relato pode suscitar vem do fato de que, como pode acontecer nos sonhos, está-se continuamente a dar voltas em torno do lar sem jamais encontrá-lo. $\mathrm{O}$ extraviado não está longe de sua casa, pelo contrário parece tê-la sempre ao seu alcance, porque o mundo é constituído de partes equivalentes entre si, porque o espaço não é um dado extenso e absoluto, mas uma função do sujeito que o habita, e para esse sujeito amazônico sempre haverá em qualquer lugar essa casa e esse roçado, o caminho rio acima e rio abaixo, o sentido beira rio e o sentido mata adentro, cada um deles com seus atributos: como diferenciar lugares nessa cosmografia? Não há que se estranhar se esse mundo sem bússola é também um mundo sem um gradiente moral: a própria terra não chama, a própria terra não puxa como supostamente chama e puxa na tradição da Odisseia e, definitivamente, o lar táo procurado é tudo menos um porto seguro. 
OSCAR CALAVIA SAEZ. O TERRITÓRIO, VISTO POR OUTROS OLHOS

Um relato como Nawawaka Misti diz muito sobre o modo em que os Yaminawa vivem e pelo qual atualizam isso que desde fora tem se rotulado como "o problema yaminawa". Em primeiro lugar, não há chance para o prestígio de uma terra ancestral, de um "lar dos antigos": a própria casa em que se habitava pouco tempo atrás é o lugar de perigo na narração. Os Yaminawa que, deslocados para a cidade, se recusam a voltar a uma aldeia minada por conflitos, náo o fazem por medo de uma certa quantia de perigo em abstrato - se assim fosse, os perigos enfrentados na cidade provavelmente superariam os riscos de uma permanência na aldeia. O que está em jogo é, antes, a intratabilidade desses conflitos: o anti-herói de Nawawaka Misti não se propôe reconquistar seu lar, do mesmo modo que não se empenha em corrigir essa sua indiscrição que o faz malquisto em toda parte. A socialidade Yaminawa não é um exercício de gestão e restauração, mas de rápida recombinação das relaçôes: antes que esforçar-se na permanência, opta pela agilidade no estabelecimento de relações novas. Se não há uma terra ancestral nem um nicho ecológico predestinado é porque não há uma rede social permanente na qual se apostem todas as cartas, como exige a opção pelo sedentarismo.

Os Yaminawa abandonam as terras onde têm se produzido um conflito, do mesmo modo que, dentro delas, abandonavam os locais de residência onde tinha se produzido a morte de algum adulto. Ou seja: há uma prioridade das relaçóes sociais, que criam território em qualquer lugar, sobre o território entendido como condição das relaçóes. Isso, por muito que fomente a instabilidade e provoque contínuas mudanças, não é "nomadismo" no sentido de um grupo permanente que se desloca através de fronteiras espaciais, porém conservando no essencial suas fronteiras sociais. A territorialidade yaminawa náo prevê fronteiras espaciais ou sociais. Antes que espacial, essa territorialidade é topológica: o espaço que ela exige é aquele que permite organizar as relaçóes de modo que proximidades e distâncias sejam eficientes. Ou seja, que facultem, de um lado, a 
REVISTA DE ANTROPOLOGIA, SÃO PAULO, USP, $20 \mathrm{I}$, V. 58 N $\mathrm{N}^{\mathrm{O}} \mathrm{I}$.

convivência e, de outro, o esquecimento. Essa necessidade não é infinita: de fato, e depois de quase dois decênios de fragmentação/dispersão sem fim aparente, os Yaminawa parecem estabilizados no conjunto de aldeias desenhado por volta do início deste século, talvez porque essa pluralidade é já ampla o bastante como para sustentar ciclos longos de fissões e fusóes.

Não se trata, portanto, de quantidade de terra, antes de qualidades polares dessa terra. Não há um meio ambiente vinculado a um modo de vida. Isto é, é obvio que há um modo de vida yaminawa que exige espaço hábil para a habitação e o roçado e mata viva para a caça, mas não há, como há por exemplo entre os Guarani (Litaiff, 2008), uma elaboração da relação entre condiçôes ecológicas e modo tradicional de vida. Provavelmente, os Yaminawa não identificam esse modo tradicional de vida por contraste com algum outro; ele é demasiado óbvio para ser situado historicamente. Malgrado a boa disposição com que os Yaminawa, dialogando com seus aliados brancos, se declaram descontentes com a cidade e fazem louvores da vida na aldeia - onde há terra e água limpa, onde náo é preciso dinheiro para comer e para morar -, na sua prática denotam uma negativa ao reconhecer a cidade como um espaço essencialmente diferente da mata. Nela, antes de tudo, tenta-se reproduzir a vida na selva: em alguma medida, as cidades acreanas ainda permitem a pesca nos rios (muito poluídos, em trechos) ou mesmo a caça em manchas subsistentes de floresta: nem sempre é impossível, até, manter pequenos roçados na periferia. Mas, mesmo à margem dessa florestalidade residual do espaço urbano, as andanças nas ruas continuam a ser análogas a atividades de caça e coleta. É isso que, com a exceção de uma minoria (vinculada direta ou indiretamente a cargos políticos e mais regularmente urbanizada), faz da presença yaminawa na cidade uma presença incômoda. À primeira vista, trata-se apenas de mendicidade (e de atividades afins, como a busca no lixo ou a eventual prostituiçáo), mas, à diferença de outras populaçóes de rua, os Yaminawa têm a capacidade 
OSCAR CALAVIA SAEZ. O TERRITÓRIO, VISTO POR OUTROS OLHOS

e a experiência de viver em outro meio; se não o fazem é, em primeiro lugar, porque as diferenças entre um e outro não são tão significativas assim. Os Yaminawa estão sempre de prontidáo para traduzir as novidades encontradas na cidade em termos da sua experiência prévia: desde o café dos brancos, identificado ao txapo (mingau de banana), até à televisão, equivalente à ayahuasca, uma comparação muito comum na Alta Amazônia, até à própria identidade dos brancos, subsumida naquela categoria preexistente de nawa. Também está longe de ser exclusivo dos Yaminawa, o hábito de chamar "mercado" aos espaços de caça na floresta: por que estranhar, entáo, se o espaço do mercado na cidade é tratado como uma espécie de território de caça? Nessa concepção perspectivista e fractal do espaço, o lugar não conta pelos seus atributos físicos, senão pelas funções que o sujeito lhe atribui, e essas funções não se alteram ao longo das migraçóes yaminawa. Só uma leitura caricata dessas afirmaçóes suporia que estamos a falar numa espécie de alucinação que os faria "crer" que a cidade é a selva. Não se trata disso, obviamente: para redundar na descrição "perspectivista", selva e cidade se diferenciam pelo seu "corpo", pela sua materialidade, e essa diferença física entre a selva e a cidade não escapa em modo algum aos Yaminawa. Apenas, essa diferença é secundária em comparação com o conjunto de relaçóes sociais que eles teimam em considerar idêntico num espaço e outro.

\section{Heterogeneidades, incompatibilidades}

Recapitulemos. Neste artigo, já fizemos alusão:

1. Aos diversos territórios Yaminawa, tanto aqueles legalmente reconhecidos quanto aquele outro constituído pelas suas perambulaçóes entre a aldeia e a cidade. 
REVISTA DE ANTROPOLOGIA, SÃO PAULO, USP, $20 \mathrm{I} 5$, V. 58 No I.

2. A uma territorialidade A, expressa no relato de Julio Isudawa, que dá fundamento à posse dos territórios, ou Terras Indígenas, legalmente atribuídas ao grupo; mas da qual é excluída, como uma anomalia, essa constante perambulação.

3. A uma outra territorialidade B (se é que esse nome pode ser usado no caso), que não faz diferença entre os espaços legalmente indígenas e os outros, cujo foco está na perambulação, e que aparece sintetizada no relato de Nawawaka Misti.

A territorialidade A é um híbrido, e com isso me refiro ao fato de que os seus componentes díspares são fáceis de reconhecer: a memória histórica do povo e um conceito de território (uma territorialidade) próprio do ordenamento jurídico, e a cosmovisáo que rege na sociedade nacional. Ou seja, é uma exposição da territorialidade yaminawa para os brancos. Deixemos claro, em primeiro lugar, um ponto: que essa territorialidade seja um híbrido náo supóe que os índios estejam a papaguear conceitos alheios. Sáo conceitos deles, língua deles porque a adquiriram dos brancos a muito custo: legitimamente indígena, enunciada por sujeitos indígenas a serviço de uma causa vital para os indígenas.

Em segundo lugar, porém, é necessário evitar a tentação de confundir essa "língua" com " $a$ " língua indígena (eles são, no mínimo, bilíngues) ou a de entender como "língua nativa" o "sotaque" com que se fala a língua alheia. Ou seja, os índios sem dúvida adquiriram dos brancos os elementos para criar essa territorialidade A, e entendem que ela é vital para a sua sobrevivência, mas isso não cancela modelos e praxes do espaço preexistentes. Quais seriam esses outros modelos e essas outras praxes? Muitos parecem buscá-los num discurso - e o texto de Isudawa é um exemplo - que póe em ação as categorias básicas da nossa concepção de território, mas com o acréscimo de alguns elementos indianistas - "lar dos ancestrais", "repouso dos ossos dos avós", "mãe natureza”... 
OSCAR CALAVIA SAEZ. O TERRITÓRIO, VISTO POR OUTROS OLHOS

Esse sotaque não é de todo involuntário: junto ao domínio do léxico "territorial", os índios têm adquirido também a noção de que, para ser eficaz, o seu discurso deve ser pronunciado "com sotaque".

Tomemos a questáo desde outro extremo: haveria, no pensamento dos outros, versôes culturalmente variáveis do nosso conceito de território, territorialidades outras? Para responder a isso, precisaríamos encarar primeiro uma outra questão: existe sequer essa nossa noção de território? Há, com certeza, no mundo dos brancos, muitas definições disponíveis de território, provindas da geografia, do direito, da etologia; outra coisa é que possam aspirar a algum tipo de hegemonia conceitual. Examinemos esse mesmo documento, que invariavelmente é citado quando se fala em territórios indígenas: a Constituição Federal. O seu artigo 231 define o que se entende por território indígena, essencialmente nos parágrafos 1 e 2, que aludem às terras "por eles habitadas em caráter permanente, as utilizadas para suas atividades produtivas, as imprescindíveis à preservação dos recursos ambientais necessários a seu bem-estar e as necessárias à sua reprodução física e cultural, segundo seus usos, costumes e tradições" as quais se destinam "à sua posse permanente, cabendo-lhes o usufruto exclusivo das riquezas do solo, dos rios e dos lagos nelas existentes".

Mas não há, nessa Constituição notável pela sua extensão e detalhe, uma definição do território "não indígena", ou do território em geral, um artigo que determine o que, como e para que é o território brasileiro. Não há explicitação de uma "territorialidade" nacional. Há, sim, numerosos artigos que tratam da definição de terras próprias da União - espaços sempre intersticiais, além de terras devolutas e terras indígenas - (art. 20), da desapropriação de terras privadas (arts. 183 e 184) ou da concessão de terras públicas (art.49), da faculdade da União de legislar quanto à proteçáo do meio ambiente e do solo (art. 24). Ou seja, quando se trata de território em geral, o que temos são restriçóes, exceçôes e condiçóes de uma regra que por sua vez não é explicitada, sem dúvida 
REVISTA DE ANTROPOLOGIA, SÃO PAULO, USP, $20 \mathrm{I} 5$, V. 58 No I.

porque, de tão obvia, parece abaixo do legislável. A julgar pelo tipo de restriçôes enumeradas, essa regra só pode ser a propriedade privada do solo. Cabe aqui nos determos numa noção que aparece várias vezes nesses artigos e constantemente na bibliografia sobre conflitos fundiários: a de terra devoluta, herança do sistema jurídico da colônia. A terra devoluta constitui a parte sólida da terra pública, descontando áreas indígenas e interstícios como margens de rios e ilhas oceânicas. O conceito de terra devoluta vale por toda uma cosmologia: esse simples adjetivo, num latim transparente, pressupóe que o domínio público alcança, no essencial, aqueles espaços cujo domínio privado cessou. A propriedade privada da terra é um dado tão solidamente estabelecido que ele pode aparecer na Constituição representado apenas pelas suas exceçôes.

Não é propósito deste artigo fazer uma arqueologia do conceito de propriedade privada do solo. Apenas é preciso lembrar que ele, em toda sua intensidade, é relativamente recente, e apenas se afirma como tal com o famoso processo de cercamento (enclosure) das terras europeias entre os séculos XVI e XVIII, ou seja, ao mesmo tempo em que acontece o loteamento das terras americanas pelas coroas do velho continente ${ }^{5}$. Antes disso, não há propriedade privada stricto sensu, mas uma complexa trama de domínios e direitos sobrepostos. Séculos depois disso, a noçáo da terra como recurso produtivo, privado salvo prova em contrário, está tão assentada que pode pairar sobre a Constituição como uma premissa tácita. Esse "nosso conceito de território", no meio do qual espera-se encontrar um espaço (um artigo 231) para as reivindicaçóes indígenas, é uma criação muito peculiar e controversa, própria do capitalismo, que ocupa tacitamente o lugar que poderia (deveria?) corresponder a um conceito geral do território.

Voltemos ao nosso assunto inicial. Essa territorialidade A, esse híbrido que é o eco-etno-território, dificilmente pode ser entendido como manifestação de um pensamento "outro". A noção de autoctonia e a 
OSCAR CALAVIA SAEZ. O TERRITÓRIO, VISTO POR OUTROS OLHOS

relação imediata com o solo e a natureza estão solidamente fincadas nas mitologias do ocidente, como uma alternativa ao regime jurídico capitalista. A noção de território indígena que consta na Constituição Federal, embora amarrada a um fato histórico específico (a presença de povos originários), representa na verdade uma alternativa ("utópica") a esse regime não declarado da propriedade privada, a única que a Constituição ousa apresentar. Ou seja, o território indígena é descrito em termos muito parecidos aos que poderiam ser usados para descrever o território nacional no seu conjunto, se assuntos como garantia do meio ambiente ou segurança alimentar fossem fundamentos, e não concessões ou cláusulas de exceção à norma da apropriação. Em certo sentido, o território indígena introduz na Constituição um conceito territorial comum que de resto falta, no mesmo sentido que as terras indígenas preenchem na prática (e a despeito da propaganda anti-indígena) toda uma série de funçôes públicas, das quais o "território não indígena" se desvencilhou, a mais visível tendo a ver com a cobertura florestal do país.

O que acima chamamos de territorialidade B é algo bem diferente, mais difícil de assimilar. Relatos como o de Nawawaka Misti nos evocam, mais do que raízes primitivas, um desarraigo bem moderno: mas quem foi que disse que índio é primitivo? Se há uma prova desse hábito de confundir o indígena com o híbrido indianista, ela pode se encontrar no escândalo com que a instabilidade yaminawa tem sido recebida - pela administração, pelos indigenistas, pelos representantes de outros grupos indígenas -, como se fosse, além de um problema para a gestão do espaço urbano, uma infidelidade às raízes nativas. Ora, é precisamente por serem fiéis ao seu passado que os Yaminawa não o diferenciam desse presente em que, de acordo com as melhores expectativas, eles deveriam se recluir nas suas terras parecendo tanto mais índios quanto fosse possível.

Que a etnicidade e os direitos dos povos originários estejam atados a um território delimitado é uma consequência quase inevitável dessa 
REVISTA DE ANTROPOLOGIA, SÃO PAULO, USP, $20 \mathrm{I} 5$, V. 58 No I.

concepção em que a condição indígena é pensada como um arquipélago de raízes territoriais fincadas num espaço feito maioritariamente de solomercadoria. Não faltam modos de atender aos direitos étnicos dos povos originários de um modo não territorial, como acontece (Viegas, comunicação pessoal) na Columbia Britânica, onde a condição de indígena garante certas vantagens fiscais, preços especiais e, por fim, uma versão específica da cidadania, enquanto as terras indígenas propriamente ditas se limitam praticamente ao espaço de habitação. Mas, no Brasil, essa perspectiva - e a própria urbanização dos índios, que é coerente com ela - só pode ser vista como um risco, porquanto a terra indígena não é apenas necessária ao sustento dos seus habitantes; ela sustenta também a própria condição indígena, sua relevância simbólica, sua legitimidade. Enquanto essa situação continuar (e não há sinais de outra coisa), a reivindicação territorial seguirá ocupando um lugar vital para o movimento indígena. E com isso não deixará de ter para os próprios índios um significado eventualmente ambíguo. Tenha-se em vista, anos atrás, o caso dos Mbyá (Garlet, 1997: 91), que, longe de exultar com a perspectiva de ter suas terras demarcadas, temiam que essa demarcação supussese uma espécie de cativeiro, que fosse um meio para mantê-los concentrados e controlados. Mas esse temor não está afinal justificado por sua história?

Para irritação dos anti-indígenas, e talvez até para desmaio dos pró -indígenas, o contencioso territorial indígena nunca parece chegar a um final feliz. Não me refiro (só) a situações como as do Nordeste ou do Sul do Brasil, onde a demografia densa e os interesses econômicos fortes opõem sérias resistências ao reconhecimento dos índios e, portanto - como manda a Constituição -, de suas terras, senão mesmo a situaçóes como as dos Yaminawa, onde uma pressão fundiária relativamente fraca facilitou o reconhecimento e a demarcação. A terra demarcada já parece demais para os oponentes da causa indígena, mas a reivindicação continua. A solução pró-indígena (cujos adversários vão ficando 
OSCAR CALAVIA SAEZ. O TERRITÓRIO, VISTO POR OUTROS OLHOS

progressivamente poderosos) procura ampliar a aplicação do modelo constitucional. Os contrários a ela - especialmente ruralistas, que também nunca têm espaço suficiente - esboçam o receio muito exagerado, porém exato em certo sentido, de que no limite isso exigiria devolver todo o território brasileiro aos índios. Não é necessário explicar por que esse projeto seria irrealizável, mas valeria a pena esclarecer que é um projeto inconcebido: não passa de ser a sombra desse outro projeto de um Brasil sem índios que, esse sim, foi várias vezes concebido e até posto em prática, felizmente com menos sucesso do que o esperado. Um país livre de brancos nunca foi, nem é agora, projeto dos índios. A falta sequer de uma versão em pequena escala desse projeto é um entrave nos processos territoriais indígenas, onde tudo seria mais fácil se os índios, de fato, tomassem os seus territórios como fortalezas, e se empenhassem em fazê-las inexpugnáveis. Longe disso, acontece que ora abrem mais uma vez essas terras aos brancos (arrendamentos, acordos com garimpeiros, relaçóes com posseiros que nelas se instalam), ora as abandonam parcialmente, e migram para a cidade. Por que essa inconstância da territorialidade indígena? Talvez seja melhor dizê-lo às claras: na medida em que pode se falar de uma territorialidade indígena diferente dessa territorialidade híbrida com que os índios têm tentado traduzir suas necessidades para as nossas condiçóes, ela é incompatível com a propriedade privada do solo. Mas seria muito mais exato, e fiel à ordem cronológica, dizer que é essa propriedade privada do solo que veio para se tornar incompatível com tudo o que antes dela definia o uso da terra pelos humanos.

Devolver o Brasil, todo ele, aos índios, não seria afinal um projeto tão descabido se contarmos com que, no Brasil, "todo mundo é índio salvo quem não é" (Viveiros de Castro, 2008). O tema das terras indígenas é, por direito próprio, um tema importante. Mas é um tema importante também porque é o índice de um desconforto muito estendido a 
REVISTA DE ANTROPOLOGIA, SÃO PAULO, USP, $20 \mathrm{I}$, V. 58 N $\mathrm{N}^{\mathrm{O}} \mathrm{I}$.

respeito de um conceito de território, o do solo-propriedade/mercadoria, que domina sem se fazer explícito. Se ele às vezes se deixa ver na forma em que gosta de ser visto -a propriedade desse agricultor que produz os alimentos para todos -, ele prefere ficar apenas implícito em outras formas, muito mais poderosas, das quais só se nos anunciam os efeitos: desequilíbrio ecológico, crises das commodities, especulação, corrupção. Isso é o bastante para que a reflexão sobre as terras indígenas seja um sinal da necessidade de se refletir sobre as terras de todos e qualquer um.

\section{Notas}

1 Cf. Calavia Sáez (2006), a cujo conteúdo este texto remete globalmente. Devo esclarecer que a grafia Yaminawa - e que se alterna no texto com a registrada oficialmente no Brasil, Jaminawa - é da minha lavra, combinando a forma brasileira com a que se registra no Peru. Optei por aumentar desse modo o campo já inflado dos etnônimos pano e de suas grafias porque, como pode se ver no texto citado logo a seguir, é nessa versão com Y onde o nome mantém seu elo com a história pregressa.

2 Um total de $76.680 \mathrm{ha}$, com um perímetro de uns $170 \mathrm{~km}$. Mamoadate tem 313.000 ha num perímetro de $336 \mathrm{~km}$.

3 Num anexo final, incluo o quadro das atuais localizaçóes yaminawa segundo o relatório de Coutinho, que descreve uma situação que essencialmente permanece até o momento atual.

4 É de praxe, quando se comentam os etnônimos dos povos Pano, oferecer essa tradução perfunctória de nawa como gente: yawanawa ou xixinawa são então gente-queixada ou gente-quati. Mas nawa apenas preenche essa função enquanto uma espécie de separador, de sufixo que denota uma espécie de diferença genérica no povo designado.

5 Esse processo é central no capítulo 27 de $O$ Capital, de Marx, e tem sido tema frequente de historiadores de inspiração marxista como Edward P. Thompson (1964; capítulo 7). 


\section{Referências bibliográficas}

Calavia Sáez, Oscar

2004 "Mapas Carnales. El territorio y la sociedad Yaminawa”. In: Surrallès Alexandre \& Hierro, Pedro. Tierra Adentro. Territorio Indígena y percepción del entorno. Copenhague, Iwgia.

2006 Onome e o tempo dos Yaminawa. Etnologia e historia dos Yaminawa do Alto Rio Acre. São Paulo, Editora da Unesp.

2006b "Na biblioteca. Micro-ensaios sobre literatura e antropología". Antropologia em Primeira Mão, v.88: 1-35.

2007 “Topología de los viajes amazónicos”. Revista de Occidente, Madrid, v. 314-15: 43-58.

Carneiro da Cunha, Manuela

1998 "Pontos de vista sobre a floresta amazônica: xamanismo e tradução". Mana, Rio de Janeiro, 4 (1): 7-22.

Coutinho, Walter

2001 Relatório de Viagem. Áreas de ocupação indígena ainda não regularizadas no Acre e sul do Amazonas. Instrução executiva n. 67/DAf. Brasília, Funai.

Ferreira, Fátima

2014 "Eles têm um quintal grande demais para o estado do Acre" Uma etnografia acerca das estratégias dos indios Jaminawá para sua permanência e trânsito entre suas aldeias e a cidade de Rio Branco - Acre. Florianópolis, trabalho de conclusão de curso, UfSC.

Garlet, Ivori José

1997 Mobilidade Mbyá: história e significação. Porto Alegre, dissertação, PUC/RS.

JaminaWA, Júlio Raimundo

2013 USI NAMEASH VIANA Somos casados de várias etnias. Monografia apresentada ao Curso de Formação Docente para Indígenas, Universidade Federal do Acre Campus Floresta.

LitAIFF Aldo

2008

“'Sem tekoa não há teko - sem terra não há cultura': estudo e desenvolvimento auto-sustentável de comunidades indígenas guarani”. Espaço Ameríndio, Porto Alegre, v. 2, n. 2: 115-123. 
REVISTA DE ANTROPOLOGIA, SÃO PAULO, USP, $20 \mathrm{I}$, V. 58 N $\mathrm{N}^{\mathrm{O}} \mathrm{I}$.

Thompson, Edward Palmer

$1964 T$ he making of the english working class. New York, Pantheon Books.

Viveiros de Castro Eduardo

2008 "No Brasil todo mundo é índio, exceto quem não é". In Sztutman, Renato (org.) Eduardo Viveiros de Castro - Entrevistas. Rio de Janeiro, Beco do Azougue.

2009 "Perspectivismo e multinaturalismo na América indígena". In A inconstância da alma selvagem. São Paulo, Cosac \& Naify.

\section{Anexo}

População jaminawa atual na bacia do rio Purus (Coutinho, 2001)

\begin{tabular}{|l|l|l|l|l|}
\hline No & TERRA INDÍGENA/RIO & ALDEIA & POPULAÇÁO & DATA \\
\hline $\mathbf{0 1}$ & Cabeceira do Rio Acre & Ananaia & 70 habitantes & Julho/2000 \\
\hline $\mathbf{0 2}$ & Cabeceira do Rio Acre & São Lourenço & 52 habitantes & Julho/2000 \\
\hline $\mathbf{0 3}$ & Cabeceira do Rio Acre & dos Patos (Santa Quitéria) & 29 habitantes & Agosto/2000 \\
\hline $\mathbf{0 4}$ & Mamoadate & Betel & 70 habitantes & Outubro/2000 \\
\hline $\mathbf{0 5}$ & Mamoadate & Cujubim & 42 habitantes & Outubro/2000 \\
\hline $\mathbf{0 6}$ & Rio Caeté & Buenos Aires & 36 habitantes & Junho/2000 \\
\hline $\mathbf{0 7}$ & Rio Caeté & Extrema & 30 habitantes & Junho/2000 \\
\hline $\mathbf{0 8}$ & Rio Iaco & Guajará & 67 habitantes & Outubro/1999 \\
\hline $\mathbf{0 9}$ & Rio Iaco & Asa Branca & 10 habitantes & Maio/2001 \\
\hline $\mathbf{1 0}$ & Rio Purus & São Paulino & 61 habitantes & Agosto/2000 \\
\hline $\mathbf{1 1}$ & Rio Purus & Caiapucá & 45 habitantes & Junho/1999 \\
\hline $\mathbf{1 2}$ & Cidade - Brasiléia & Samaúma & 11 habitantes & Julho/2000 \\
\hline $\mathbf{1 3}$ & Cidade - Rio Branco & Diversos & 30 habitantes & Novembro/2000 \\
\hline TOTAL & & $\mathbf{5 5 3 ~ h a b i t a n t e s ~}$ & \\
\hline
\end{tabular}


OSCAR CALAVIA SAEZ. O TERRITÓRIO, VISTO POR OUTROS OLHOS

\section{Another Way of Understanding Territory}

ABSTRACT: The Yaminawa of Acre (Southwestern Amazon, Brazil) have been considered by government officials and NGOs as a political problem, due to their difficult insertion in the multiculturalist territorial system. Notwithstanding their success in having their lands legally recognized, their groups, constantly split by inner conflicts, remain wandering between ethnic lands and cities. In this paper, we examine Yaminawa political discourse and myths, searching for the conceit of territory that underlie this practice. It can be defined as a sociological and topological rather than ecological conceit. Distance is the main attribute of territory: shifting social arrangements must be modulated by adequate distances. The idea of ethnic territory as an ecological space, useful to reproduce traditional ways of life, is frequently expressed by Yaminawa leaders. However, it is designed, mainly, to fit into the western (and brazilian) preconceptions about the embeddedment of indigenous peoples in the natural world.

KEYWORDS: Yaminawa, Territory, Fractal, Perspectivism, Topology, Amazon.

Recebido em outubro de 2014. Aceito em março de 2015. 